\title{
Regulation of Subtypes of $\beta$-Adrenergic Receptors in Rat Brain Following Treatment with 6-Hydroxydopamine
}

\author{
Eric W. Johnson, ${ }^{\mathrm{a}}$ Barry B. Wolfe, ${ }^{\mathrm{b}}$ and Perry B. Molinoff \\ Department of Pharmacology, University of Pennsylvania School of Medicine, Philadelphia, Pennsylvania 19104
}

\begin{abstract}
The technique of quantitative autoradiography has been used to localize changes in the densities of subtypes of $\beta$-adrenergic receptors in rat brain following treatment with 6-hydroxydopamine. Previously reported increases in the density of $\beta_{1}$-adrenergic receptors in the cerebral cortex were confirmed. The anatomical resolution of autoradiography made it possible to detect changes in the density of $\beta_{2}$-adrenergic receptors in the cortex and in a number of other brain regions. The density of $\beta_{1}$-adrenergic receptors increased from 30 to $50 \%$ depending on the region of the cortex being examined. The increase in the somatomotor cortex was greater than that in the frontal or occipital cortex. The increase in the density of $\beta_{2}$-adrenergic receptors in the cortex was not as widespread as that of $\beta_{1}$-adrenergic receptors and occurred primarily in frontal cortex, where the density of receptors increased by $40 \%$. The densities of both $\beta_{1}$ - and $\beta_{2^{-}}$ adrenergic receptors increased in a number of forebrain, thalamic, and midbrain structures. Selective changes in the density of $\beta_{1}$-adrenergic receptors were observed in the superficial gray layer of the superior colliculus and in the amygdala. The density of $\beta_{2}$-adrenergic receptors increased in the caudate-putamen, the substantia nigra, and the lateral and central nuclei of the thalamus, whereas the density of $\beta_{1}$ adrenergic receptors did not change in these regions. The densities of both subtypes of $\beta$-adrenergic receptors increased in the hippocampus, the cerebellum, the lateral posterior nucleus of the thalamus, and the dorsal lateral geniculate. One of the largest changes observed occurred in the dorsal lateral geniculate, where the density of $\beta_{2}$-adrenergic receptors increased by $150 \%$. Regional changes in the density of one subtype were independent of changes in the density of the other subtype. These results suggest that both $\beta_{1}$ - and $\beta_{2}$-adrenergic receptors are functionally innervated in rat brain.
\end{abstract}

Several groups of investigators have reported that denervation of adrenergically innervated tissues resulted in supersensitivity

\footnotetext{
Received May 20, 1988; revised Nov. 17, 1988; accepted Nov. 21, 1988.

This work was supported by NIH Grants GM 34781, GM 31155, NS 18479 , NS 22040, GM31155, and HL 07502. B.B.W. is an Established Investigator of the American Heart Association. We would like to acknowledge the support and direction provided by the late Dr. Thomas C. Rainbow during the early stages of this project and the Esther $A$. and Joseph Klingenstein Fund, Inc.

Correspondence should be addressed to Perry B. Molinoff, M.D., at the above address.

a Present address: Department of Psychiatry/CMHC, 34 Park Street, Yale University School of Medicine, New Haven, CT 06508.

b Present address: Department of Pharmacology, Georgetown University School of Medicine, 3900 Reservoir Rd., N.W., Washington, DC 20007.

Copyright (C) 1989 Society for Neuroscience $0270-6474 / 89 / 072297-09 \$ 02.00 / 0$
}

to exogenously applied norepinephrine (NE) (Iversen and Uretsky, 1970; Uretsky and Iversen, 1970; Palmer, 1972; Kalisker et al., 1973; Kostrzewa and Jacobowitz, 1974; Sachs and Jonsson, 1975; Sporn et al., 1976). The potent neurotoxin 6-hydroxydopamine (6-OHDA) causes a widespread and apparently permanent destruction of catecholaminergic neurons. Since it does not cross the blood-brain barrier in adult animals, it must be injected directly into the CNS to cause destruction of adrenergic neurons in the CNS. Intraventricular injection of 6-OHDA into the lateral ventricles has been shown to result in an almost complete destruction of central adrenergic neurons as demonstrated by a nearly complete loss of forebrain NE. Administration of 6-OHDA resulted in an increase of approximately $50 \%$ in the density of cortical $\beta$-adrenergic receptors (Sporn et al., $1976,1977)$. This increase was due to a change in the density of $\beta_{1}$-adrenergic receptors, while the density of $\beta_{2}$-adrenergic receptors was unchanged (Minneman et al., 1979a). Similarly, the density of $\beta_{1}$-adrenergic receptors was reported to increase by $100 \%$ in the cerebellum after intracisternal administration of 6-OHDA (Wolfe et al., 1982). Again, the density of $\beta_{2}$-adrenergic receptors did not appear to change. These observations led to the hypothesis that only $\beta_{1}$-adrenergic receptors were functionally innervated. $\beta_{2}$-Adrenergic receptors were thought to receive a very low level of stimulation or to be associated with non-neuronal, glial, or vascular elements. Consistent with a non-neuronal localization of $\beta_{2}$-adrenergic receptors was the observation that small regional variations occurred in the density of $\beta_{2}$-adrenergic receptors, whereas the density of $\beta_{1}$-adrenergic receptors varied markedly from region to region.

Rainbow et al. (1984) used quantitative autoradiography to map the density and distribution of $\beta_{1}$ - and $\beta_{2}$-adrenergic receptors in rat CNS. They reported that the 2 subtypes were heterogeneously distributed throughout the various anatomical regions of the brain. $\beta_{2}$-Adrenergic receptors were shown to be the predominant subtype in a number of forebrain and thalamic nuclei, as well as in the cerebellum and in layer 4 of the cortex. $\beta_{1}$-Adrenergic receptors were the predominant form of $\beta$-adrenergic receptor in most cortical areas and in most thalamic and midbrain nuclei. This heterogeneous distribution of subtypes of $\beta$-adrenergic receptors suggested that both subtypes may play a functional role.

The technique of quantitative autoradiography is useful for investigating the effects of physiological or pharmacological interventions on the distribution of receptor subtypes in the CNS (Rainbow et al., 1982). With the increased anatomical resolution offered by autoradiography, we were able to identify regions of the brain where the density of one or the other subtype of $\beta$-adrenergic receptor changed in response to denervation. The differing distributions of these changes indicate that the subtypes 
of $\beta$-adrenergic receptors may be associated with functionally distinct patterns of innervation.

\section{Materials and Methods}

Tissue preparation and production of autoradiograms. Adult male Sprague-Dawley rats $(150-200 \mathrm{gm})$ were killed by decapitation. The brains were rapidly removed, placed on glass microscope slides ventral side down, and frozen in powdered dry ice. Frozen brains were stored at $-80^{\circ} \mathrm{C}$ until they were to be sectioned. Prior to sectioning, brains were mounted on cryostat chucks and allowed to warm to $-10^{\circ} \mathrm{C}$. Sequential $32 \mu \mathrm{m}$ coronal sections were cut and thaw-mounted onto gelatin-coated glass slides. Pairs of sequential sections were mounted on each slide, with every ninth section being used for cresyl violet staining. The stained sections were matched with anatomical levels as defined in a stereotaxic atlas of the rat brain (Paxinos and Watson, 1982). This allowed an accurate match of the brain areas to be analyzed by making it possible to correlate the anatomical levels of the sections from both the control and treated brains.

The slide-mounted sections were stored at $-80^{\circ} \mathrm{C}$ until they were to be used. The night before an assay, sections were placed in a vacuum desiccator at $4^{\circ} \mathrm{C}$. One-half hour before the assay, the sections were allowed to warm to room temperature. This 2-step drying procedure was found to minimize flaking of tissue during the incubation. Incubations were carried out in plastic carboys. The incubation buffer used throughout consisted of $20 \mathrm{~mm}$ Tris (pH 7.4) and $135 \mathrm{~mm} \mathrm{NaCl}$ at $24^{\circ} \mathrm{C}$ (Tris saline). Sections were incubated with Tris saline and ${ }^{125}$ I-iodopindolol (125I-IPIN), with or without various inhibitors, for the desired length of time at $24^{\circ} \mathrm{C}$. Sections were then washed with Tris saline at $4^{\circ} \mathrm{C}$. In some experiments, sections were wiped from the slides using glass-fiber filters, and the amount of radioactivity present was determined with a gamma counter. If the sections were to be used for autoradiography, they were rapidly dipped in distilled $\mathrm{H}_{2} \mathrm{O}$ at $4^{\circ} \mathrm{C}$ to reduce the concentration of buffer salts that interfere with the generation of autoradiograms and dried on a slide drier at $60^{\circ} \mathrm{C}$. Dried slides were then apposed to LKB-Ultrofilm for $24 \mathrm{hr}$. Tissue standards prepared with ${ }^{125}$ I were included in each cassette to allow standardization of the results. The standards allow optical density readings to be converted to $\mathrm{fmol} / \mathrm{mg}$ of protein. Developed autoradiograms were analyzed using a microcomputer-based densitometer with an anatomical resolution of $100 \mu \mathrm{m}$.

Homogenized tissue preparation. For some of the studies designed to establish assay conditions, a large number of anatomically uniform sections was required. There are few areas of the rat brain from which more than 25 sequential sections uniform in respect to size and anatomical composition can be obtained. To circumvent this problem, a homogenate of rat forebrain was used. Rat forebrain (minus cerebellum, brain stem, and olfactory bulbs) was minced thoroughly on a glass plate kept on ice. The minced brain was put into plastic tubes along with 1$2 \mathrm{ml}$ Tris saline. This mixture was homogenized using a Brinkmann Polytron with a medium-sized probe for $10 \mathrm{sec}$ at a setting of 6 . The tissue was then sedimented at $20,000 \times g$ for $30 \mathrm{~min}$ at $4^{\circ} \mathrm{C}$. The supernatant was decanted and the pellet mixed with a glass rod. The mixed pellet was then carefully loaded into a syringe barrel used as a mold. Care was taken to minimize the formation of bubbles. The mold was frozen in powdered dry ice. Frozen homogenized tissue was removed from the mold, mounted on a cryostat chuck, and sectioned as described above. This procedure provided a virtually unlimited number of uniform sections.

Tissue standards. Tissue standards were prepared using the homogenized tissue preparation described above. Varying aliquots of ${ }^{125}$ I-IPIN (3-4 million $\mathrm{cpm} / 5 \mu \mathrm{l}$ ) were added to test tubes containing aliquots of homogenate and mixed thoroughly. The radioactive tissue was sectioned as described above. Several sections from each standard were placed in small plastic tubes. An aliquot $(200 \mu 1)$ of a solution containing $0.1 \mathrm{~N}$ $\mathrm{NaOH}$ and $0.1 \%$ Triton $\mathrm{X}-100$ was added to each tube and the tissue thoroughly homogenized with a small Teflon homogenizer. Equal aliquots of each standard were taken for determination of radioactivity using a gamma counter and for protein determination using the method of Bradford (1976). BSA dissolved in the $\mathrm{NaOH} /$ Triton X-100 buffer was used as the protein standard. Additional sections from each standard were thaw-mounted onto slides. These standards were allowed to dry and were stored in a desiccator at room temperature. Autoradiograms were generated with the tissue sections on the day the standards were made. The optical densities of these autoradiograms were correlated with the protein and radioactivity data for each standard, taking into account the time delay between the time the standards were calibrated and the time when the experimental autoradiograms were prepared.

Characterization experiments. Sequential sections corresponding to Paxinos and Watson (1982) levels 10-15 were obtained from a number of rat brains. These sections were incubated with 50 pM ${ }^{125}$ I-IPIN in Tris saline at $24^{\circ} \mathrm{C}$ for varying lengths of time. After incubation, the sections were washed at $4^{\circ} \mathrm{C}$ in Tris saline for $40 \mathrm{~min}$ before being removed from the slides with glass-fiber filters.

Experiments were also carried out to optimize the wash time. Sections corresponding to Paxinos and Watson levels $10-15$ were incubated with $150 \mathrm{pM}^{125} \mathrm{I}$-IPIN in Tris saline at $24^{\circ} \mathrm{C}$ for $60 \mathrm{~min}$. The sections were then washed with Tris saline at $4^{\circ} \mathrm{C}$ for varying lengths of time before being removed from the slides.

Inhibition curves for $l$-isoproterenol and $l$ - and $d$-propranolol were prepared by incubating sequential tissue sections with ${ }^{125}$ I-IPIN in Tris saline at $24^{\circ} \mathrm{C}$ for $60 \mathrm{~min}$ in the presence of varying concentrations of each drug. The sections were then washed for 30 min with Tris saline at $4^{\circ} \mathrm{C}$ before being removed from the slides.

Subtype analysis. Inhibition curves generated with the subtype-selective antagonists ICI 118,551 ( $\beta_{2}$-selective) and ICI 89,406 ( $\beta_{1}$-selective) (see Rainbow et al., 1984) were analyzed for a 2 -site fit by nonlinear least-squares regression analysis using the FITCOMP program on the NIHsponsored PROPHE'I computer system. The data were fit to the following 2-site equation:

$$
B=\frac{B_{1} * I C_{1}}{I+I C_{1}}+\frac{B_{2} * I C_{2}}{I+I C_{2}}
$$

where $B$ is the amount of radioligand bound, $B_{1}$ and $B_{2}$ are the total number of sites of each subtype labeled by this concentration of radioligand, $I$ is the concentration of the competing ligand, and $I C_{1}$ and $I C_{2}$ are the concentrations of competing ligand that inhibit $50 \%$ of the binding to each subtype (Hancock et al., 1979; Minneman and Molinoff, 1980; Neve et al., 1986).

Treatment with 6-OHDA. Adult male Sprague-Dawley rats (150-200 $\mathrm{gm}$ ) were injected intraventricularly with a total dose of $400 \mu \mathrm{g}$ (free base) of 6-OHDA dissolved in $20 \mu \mathrm{l}$ of normal saline containing $0.1 \%$ ascorbic acid adjusted to $\mathrm{pH} \mathrm{5.0.} \mathrm{Control} \mathrm{animals} \mathrm{were} \mathrm{injected} \mathrm{with}$ vehicle alone. The animals were injected bilatcrally, with onc-half of the dose being injected into the left ventricle on day 1 and the other half being injected into the right ventricle on day 2 . Injections were made through small burr holes drilled $3.2 \mathrm{~mm}$ caudal to bregma and $5.0 \mathrm{~mm}$ lateral to the superior sagittal suture. Drug was administered into the lateral ventricles, $5.0 \mathrm{~mm}$ down from the surface of the skull. Coordinates were verified by injecting aliquots of India ink and sectioning the brains to observe localization of ink in the ventricles. All injections were made with a Kopf stereotaxic apparatus using a $20 \mu \mathrm{l}$ Hamilton syringe with a 26 gauge needle. Rats were anesthetized with methoxyflurane prior to surgery. Anesthesia was maintained for the 58 min needed to complete the procedure. Scalp wounds were closed with wound clips, and animals were kept warm until they recovered from surgery. Animals were killed 2 weeks after the initial injection. Brains were either prepared for autoradiography as previously described, or, in some cases, brains were prepared for regional analysis of catecholamine content using high-performance liquid chromatography.

Determination of catecholamine content. Animals were killed by decapitation and the brains rapidly removed. Olfactory bulbs and spinal cord were removed, and the brain was dissected into the following anatomically distinct regions: cortex, caudate, cerebellum, and hippocampus. The brain regions were weighed to allow for standardization of sample size. Each sample was placed in a plastic tube containing 1 $\mathrm{ml}$ of ice-cold $0.1 \mathrm{~N}$ perchloric acid. In each case, dihydroxybenzoic acid ( $5 \mathrm{ng}$ ) was added as an internal standard. This mixture was homogenized with a Brinkmann Polytron at setting 6 for $10 \mathrm{sec}$ at $4^{\circ} \mathrm{C}$. The homogenized tissue was centrifuged at $20,000 \times \mathrm{g}$ for $30 \mathrm{~min}$ at $4^{\circ} \mathrm{C}$ and stored at $-80^{\circ} \mathrm{C}$ until used. A $200 \mu$ l aliquot of the supernatant was extracted using acid-washed alumina according to the method of Anton and Sayre (1962). Aliquots of this concentrate were analyzed using HPLC with electrochemical detection.

Reserpine treatment. Rats were injected intraperitoneally with a dose of $5 \mathrm{mg} / \mathrm{kg}$ of reserpine $(25 \mathrm{mg}$ dissolved in $125 \mu \mathrm{l}$ glacial acetic acid diluted to $5 \mathrm{ml}$ with $95 \%$ ethanol). Control animals were injected with vehicle alone. Animals were killed $24 \mathrm{hr}$ after the injection. Before freezing the brains for autoradiography, the front one-third of the fore- 
Table 1. Affinities of subtypes of $\beta$-adrenergic receptors in the rat cortex for the selective antagonists ICI 118,551 and ICI 89,406

\begin{tabular}{lcc} 
& ICI 118,551 & ICI 89,406 \\
\hline $\mathrm{IC}_{50} \beta_{1}$ & $360 \pm 28$ & $0.40 \pm 0.03$ \\
$\mathrm{IC}_{50} \beta_{2}$ & $0.41 \pm 0.02$ & $280 \pm 63$ \\
$\% \beta_{1}$ & $61 \pm 3$ & $65 \pm 3$ \\
$\% \beta_{2}$ & $39 \pm 6$ & $35 \pm 2$ \\
\hline
\end{tabular}

Incubation conditions are as described in Materials and Methods. $\mathrm{IC}_{50}$ values were determined using the NEWFITSITES program on the PROPHET network and are expressed in $\mathrm{nM}(n=4)$.

brain (minus the olfactory bulbs) corresponding to the region just anterior to the optic chiasm was removed and prepared for HPLC analysis of catecholamines as previously described. The rest of the brain was frozen in powdered dry ice and used for autoradiographic assay of the subtypes of $\beta$-adrenergic receptors.

Statistics. In all cases comparisons between control and treated animals were made using Student's $t$ test. A significance level of $p \leq 0.01$ was used as the definition of statistical significance. The density of receptors for each structure is an average of values obtained from all the anatomical levels in which the structure was identified. Where appropriate, the values obtained from each anatomical level are given. Nonspecific binding has been subtracted in each case.

Materials. (-)-Pindolol was a gift from Sandoz (Hanover, NJ). ICI 118,551 and ICI 89,406 were gifts from ICI Pharmaceuticals Group (Wilmington, DE). 6-Hydroxydopamine hydrobromide, (-)-isoproterenol bitartrate, GTP, and reserpine were purchased from Sigma Chemical Corporation (St. Louis). $\mathrm{Na}^{125} \mathrm{I}$ was obtained from New England Nuclear (Boston). Adult male Sprague-Dawley rats (150-200 gm) were purchased from Charles River (Boston).

\section{Results}

\section{Characterization experiments}

Sequential sections of rat brain were incubated with 50 pM ${ }^{125} \mathrm{I}$ IPIN with or without $100 \mu \mathrm{M}$ isoproterenol for varying periods of time. The sections were then removed from the slides, and the amount of spccifically bound radioactivity was detcrmined using a gamma counter. Binding reached equilibrium after approximately $60 \mathrm{~min}$ at $24^{\circ} \mathrm{C}$. Unlike conventional binding assays using tissue homogenates, extensive washing is needed to reduce the nonspecific binding to the tissue sections used for autoradiography. Washing the sections for $30 \mathrm{~min}$ at $4^{\circ} \mathrm{C}$ markedly reduced nonspecific binding without significantly affecting specific binding. Binding of ${ }^{125}$ I-IPIN was inhibited in a stereospecific manner, with $l$-propranolol being about 100 -fold more potent than $d$-propranolol in inhibiting binding of ${ }^{125}$ I-IPIN. $l$-Isoproterenol inhibited binding with an $\mathrm{IC}_{50}$ value of $0.3 \mu \mathrm{M}$. Nonspecific binding of ${ }^{125}$ I-IPIN was defined as binding that occurs in the presence of $100 \mu \mathrm{M} l$-isoproterenol (Fig. $1 A$ ).

Inhibition of the binding of ${ }^{125}$ I-IPIN by the selective $\beta$-adrenergic receptor subtype-specific antagonists ICI 118,551 and ICI 89,406 was markedly biphasic (Fig. $1 B$ ). ICI 89,406 is a potent inhibitor of binding to $\beta_{1}$-adrenergic receptors and ICI 118,551 is a potent antagonist of binding to $\beta_{2}$-adrenergic receptors (see Rainbow et al., 1984). Each drug was approximately 1000 -fold more potent at blocking the binding of ${ }^{125}$ I-IPIN to one subtype than to the other. Analysis of these inhibition curves revealed that $63 \%$ of the receptors had the pharmacological specificity of $\beta_{1}$-adrenergic receptors and $37 \%$ that of $\beta_{2}$-adrenergic receptors (Table 1 ). Concentrations of each of the drugs that would allow $150 \mathrm{pm}^{125} \mathrm{I}-\mathrm{IPIN}$ to bind almost exclusively to one subtype while blocking binding to the other were determined. Binding of ${ }^{125}$ I-IPIN to $\beta_{1}$-adrenergic receptors was defined as
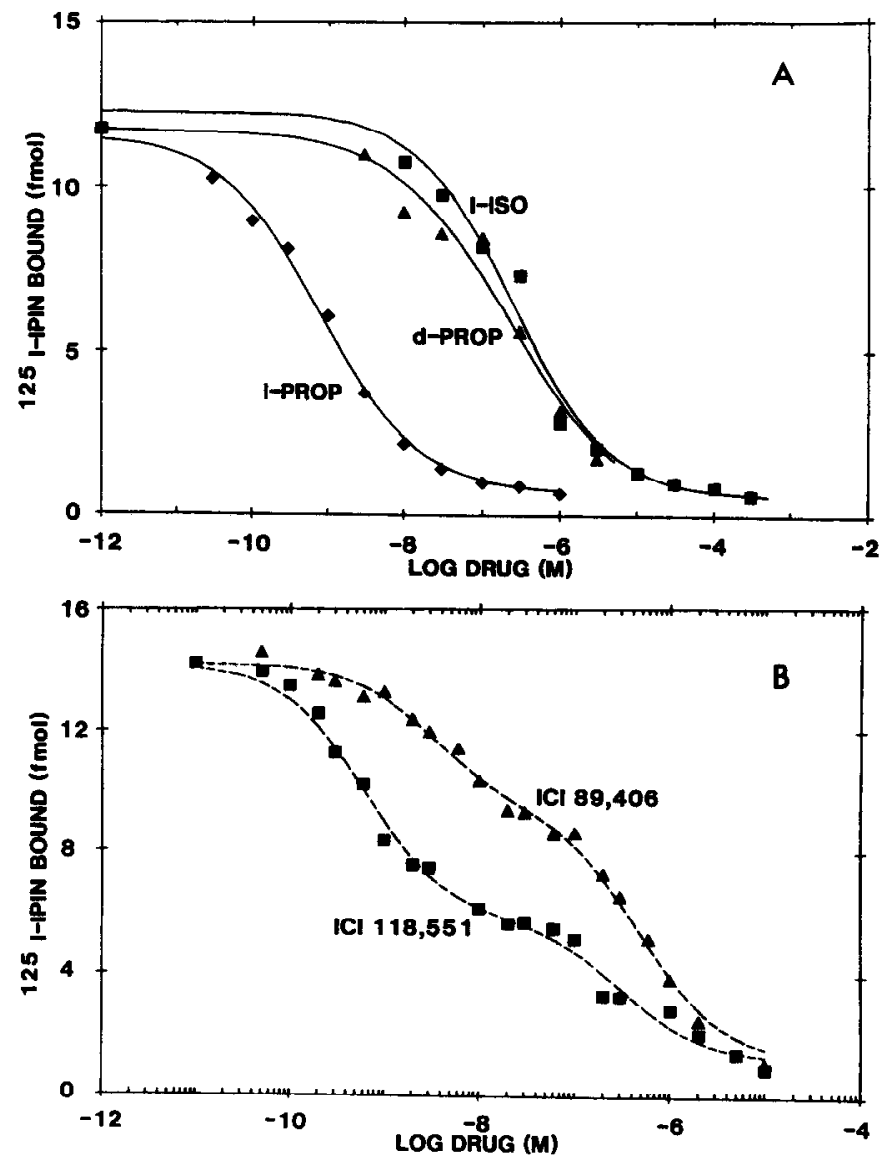

Figure 1. Inhibition of the binding of ${ }^{125}$ I-IPIN by agonists and antagonists. $A$, Sequential $32 \mu \mathrm{m}$ coronal sections of rat brain corresponding to Paxinos and Watson (1982) levels 10-15 were incubated with $150 \mathrm{pM}{ }^{125}$ I-IPIN in the presence of varying concentrations of either $l$-isoproterenol, $d$-propranolol, or $l$-propranolol for $60 \mathrm{~min}$ at $24^{\circ} \mathrm{C}$. The sections were then washed for $30 \mathrm{~min}$ at $4^{\circ} \mathrm{C}$ and wiped from the slides with glass-fiber filters. The radioactivity present was determined with a gamma counter. $B$, Sequential sections were obtained from a homogenized, frozen preparation of rat forebrain as described in Materials and Methods. The sections were incubated with $150 \mathrm{pm}^{125}$ I-IPIN and varying concentrations of either ICI 118,551 or ICI 89,406 for $60 \mathrm{~min}$ at $24^{\circ} \mathrm{C}$. The sections were then washed for $30 \mathrm{~min}$ in buffer at $4^{\circ} \mathrm{C}$ before being wiped from the slides with glass-fiber filters.

binding that occurred in the presence of $12 \mathrm{nM}$ ICI 118,551 minus nonspecific binding. Binding of ${ }^{125}$ I-IPIN to $\beta_{2}$-adrenergic receptors was defined as binding that occurred in the presence of $11 \mathrm{nM}$ ICI 89,406 minus nonspecific binding. Under these conditions, the binding of ${ }^{125}$ I-IPIN to $\beta_{2}$-adrenergic receptors was inhibited by $97 \%$, while binding to the $\beta_{1}$-adrenergic receptors was inhibited by only $3 \%$.

\section{Effect of 6-OHDA}

Intraventricular injection of $400 \mu \mathrm{g} 6$-OHDA free base resulted in a reduction in the levels of NE in all 4 brain regions examined after 1 week as measured by HPLC analysis. There was a reduction of NE levels in the cortex $(96 \%)$, caudate $(91 \%)$, cerebellum ( $96 \%)$, and hippocampus $(99 \%)$ of treated rats compared with control animals. Dopamine levels were also found to be reduced in the regions examined; however, these reductions were not as large as the reduction seen in levels of NE. The depletion of dopamine ranged from approximately $30 \%$ in the cerebellum to approximately $70 \%$ in the cortex. 


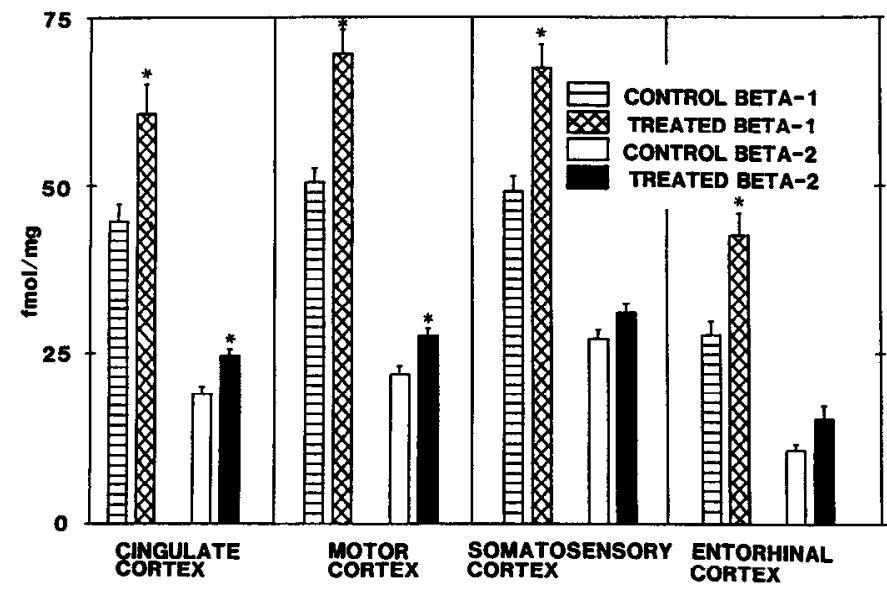

Figure 2. Effect of 6-OHDA on the subtypes of $\beta$-adrenergic receptors in cortical regions of rat brain. Tissue sections from treated and control animals were aligned using cresyl violet-stained sections taken periodically while sectioning each brain. Sections from each brain were sorted into 4 groups, one for determining total binding of ${ }^{125}$ I-IPIN, one for determining nonspecific binding, and one each for determining binding of ${ }^{125}$ I-IPIN to $\beta_{1}$ - and $\beta_{2}$-adrenergic receptors as described in Materials and Methods. The autoradiograms were analyzed using a computerbased densitometer with an anatomical resolution of approximately 100 $\mu \mathrm{m}$. The results shown are an average of the values for all of the anatomical levels in which the structure is present. The regions analyzed were defined using the Paxinos and Watson atlas (1982). $\left(^{*} p \leq 0.01\right)$

The distributions of subtypes of $\beta$-adrenergic receptors were compared in control and treated animals. Regional increases in the densities of both $\beta_{1}$ - and $\beta_{2}$-adrenergic receptors were observed. As expected, large increases in the density of $\beta_{1}$-adrenergic receptors were observed in cortical regions (Figs. 2-4). The density of $\beta_{1}$-adrenergic receptors increased in cingulate, motor, somatosensory, and entorhinal cortical areas. The magnitude of the increase was between 30 and $50 \%$, consistent with the changes seen using homogenates of cerebral cortex (Sporn et al., 1976, 1977; Harden et al., 1977; Minneman et al., 1979a, b). The density of $\beta_{2}$-adrenergic receptors increased significantly in cingulate and motor cortex but did not change significantly in somatosensory or entorhinal cortex. In the cortical areas in which increases in the density of $\beta_{2}$-adrenergic receptors were observed, the percentage increase in the density of $\beta_{2}$-adrenergic receptors was less than that of $\beta_{1}$-adrenergic receptors.

An unexpected observation in the cingulate cortex related to the distribution of subtypes of $\beta$-adrenergic receptors throughout the various anatomical levels in which the structure was identified. A rostral-to-caudal gradient of subtypes of $\beta$-adrenergic receptors exists within the cingulate cortex (Fig. 5). An increase in the density of both $\beta_{1}$ - and $\beta_{2}$-adrenergic receptors was apparent at all levels of the cingulate cortex, and the rostralto-caudal gradient in the density of receptors persisted even after treatment with 6-OHDA.

In addition to increases in the density of $\beta_{2}$-adrenergic receptors in some cortical areas, increases in the density of $\beta_{2}$-adrenergic receptors were observed in a number of forebrain and midbrain structures. Increases of $50 \%$ or more were seen in both the medial and lateral septal forebrain nuclei (Figs. 3, 6). The densities of $\beta_{1}$-adrenergic receptors did not change in these regions. The densities of $\beta_{2}$-adrenergic receptors also increased significantly in a number of thalamic nuclei (Figs. 4, 6; Table
Table 2. Changes in the densities of $\beta_{1}$ - and $\beta_{2}$-adrenergic receptors in selected areas of the basal ganglia, thalamus, and amygdala

\begin{tabular}{rll} 
Control \pm SEM & Treated \pm SEM & Structure \\
\hline$\beta_{1}$ Receptors & & \\
$53.0 \pm 2.7$ & $57.4 \pm 3.4$ & Caudate-putamcn \\
$75.2 \pm 5.6$ & $72.3 \pm 3.6$ & Nucleus accumbens \\
$31.9 \pm 1.9$ & $33.2 \pm 2.2$ & Globus pallidus \\
$30.9 \pm 1.2$ & $36.2 \pm 1.9$ & Substantia nigra \\
$31.1 \pm 1.7$ & $37.5 \pm 2.0$ & Bed nucleus, stria terminalis \\
$54.5 \pm 3.9$ & $60.3 \pm 5.4$ & Nucleus gelatinosus \\
$27.0 \pm 2.3$ & $39.5 \pm 3.7$ & Paraventricular nucleus $^{a}$ \\
$31.8 \pm 2.3$ & $46.8 \pm 2.8$ & Medial central nucleus $^{a}$ \\
$32.3 \pm 3.3$ & $49.4 \pm 3.1$ & Lateral central nucleus $^{a}$ \\
$36.1 \pm 3.8$ & $49.6 \pm 2.6$ & Amygdala \\
$\beta_{2}$ Receptors & & \\
$25.4 \pm 1.5$ & $32.8 \pm 1.5$ & Caudate-putamen $^{a}$ \\
$37.0 \pm 1.5$ & $42.3 \pm 1.5$ & Nucleus accumbens $^{a}$ \\
$23.7 \pm 1.0$ & $25.3 \pm 2.1$ & Globus pallidus $^{a}$ \\
$21.2 \pm 2.4$ & $30.8 \pm 1.6$ & Substantia nigra $^{a}$ \\
$23.1 \pm 2.0$ & $33.3 \pm 1.8$ & Bed nucleus, stria terminalis $^{a}$ \\
$20.0 \pm 2.2$ & $30.0 \pm 2.3$ & Nucleus gelatinosus $^{a}$ \\
$26.0 \pm 3.4$ & $33.8 \pm 2.5$ & Paraventricular nucleus \\
$34.1 \pm 3.5$ & $47.4 \pm 2.8$ & Medial central nucleus $^{a}$ \\
$26.2 \pm 1.8$ & $35.3 \pm 2.3$ & Lateral central nucleus $^{a}$ \\
$14.5 \pm 1.1$ & $17.8 \pm 1.7$ & Amygdala $^{a}$
\end{tabular}

Incubation conditions are as described in Materials and Methods. Results are fmol/mg protein \pm SEM $(n=5)$.

${ }^{a} p \leq 0.01$.

2). Changes were observed in the lateral and medial dorsal nuclei (Figs. 4, 6), in the lateral posterior thalamic nucleus (Figs. 4, 6), and in the dorsal lateral geniculate (Figs. 4, 6).

Changes observed in a number of basal ganglion and midbrain structures are compared in Table 2. Changes in basal ganglion structures such as the caudate-putamen and the substantia nigra were exclusively increases in the density of $\beta_{2}$-adrenergic receptors (Figs. 3, 4; Table 2), whereas the changes seen in other regions such as the lateral and medial central nuclei of the thalamus included increases in the densities of both $\beta_{1^{-}}$and $\beta_{2^{-}}$ adrencrgic reccptors (Tablc 2).

Changes in the densities of both $\beta_{1}$ - and $\beta_{2}$-adrenergic receptors were also seen in areas CA 1 and $C A 3$ of the hippocampus (Figs. 4,7 ). Increases in the density of $\beta_{1}$-adrenergic receptors were seen in the amygdala (Table 2). There was a large increase in the density of $\beta_{1}$-adrenergic receptors in the superficial layer of the superior colliculus with no change in the density of $\beta_{2}$ adrenergic receptors (Fig. 7). Finally, in the granular cell and molecular layers of the cerebellum, increases in the densities of both subtypes of $\beta$-adrenergic receptors were observed (Fig. 7).

Saturation curves for binding of ${ }^{125}$ I-IPIN for both control and treated animals were carried out in the motor cortex (Fig. 8). Scatchard (1949) plots of the mean values obtained for 6 rats for each concentration of ${ }^{125}$ I-IPIN are shown in the inset of Figure 8. No significant change in the $K_{d}$ value for ${ }^{125}$ I-IPIN in the motor cortex was observed (Fig. 8, inset). The $B_{\max }$ value did increasc significantly, indicating an incrcasc in the density of $\beta$-adrenergic receptors after treatment with 6-OHDA (Fig. 8, inset). These results were consistent with those obtained using a single concentration of ${ }^{125}$ I-IPIN, where there was an increase 

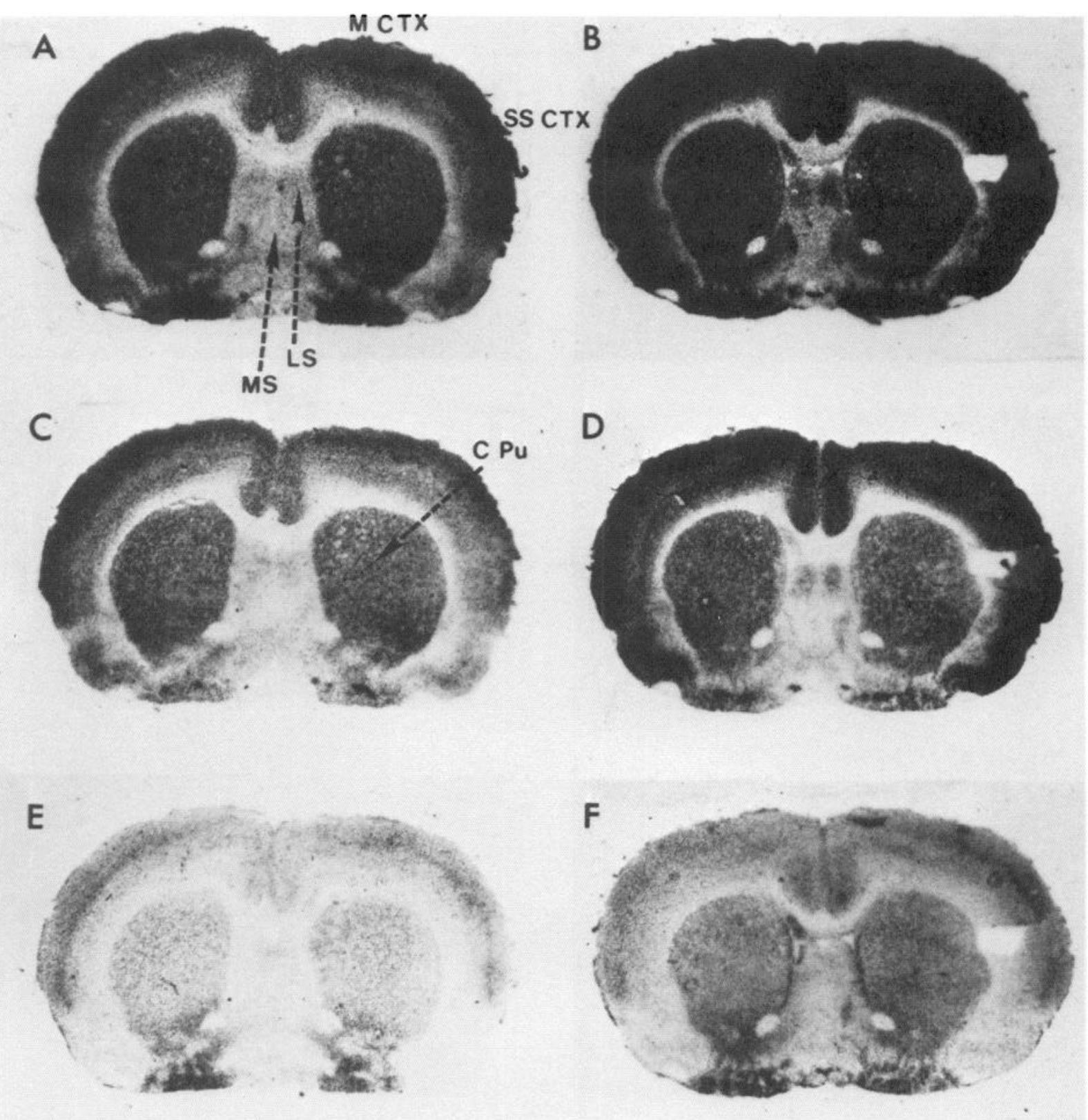

G

H

Figure 3. Autoradiograms of the binding of ${ }^{125}$ I-IPIN to sections of rat brain at a level corresponding to Paxinos and Watson (1982) level 14. Incubation conditions and the generation of autoradiograms are described in Materials and Methods. Comparisons of control $(A, C, E, G)$ and 6-OHDA-treated $(B, D, F, H)$ animals are made for total $\beta$-adrenergic receptors $(A, B), \beta_{1}$-adrenergic receptors $(C, D), \beta_{2}$-adrenergic receptors $(E$, $F$ ), and nonspecific binding sites $(G, H)$. MCTX, motor cortex; $S S C T X$, somatosensory cortex; $L S$, lateral septal nucleus; $M S$, medial septal nucleus; $C P u$, caudate-putamen. 

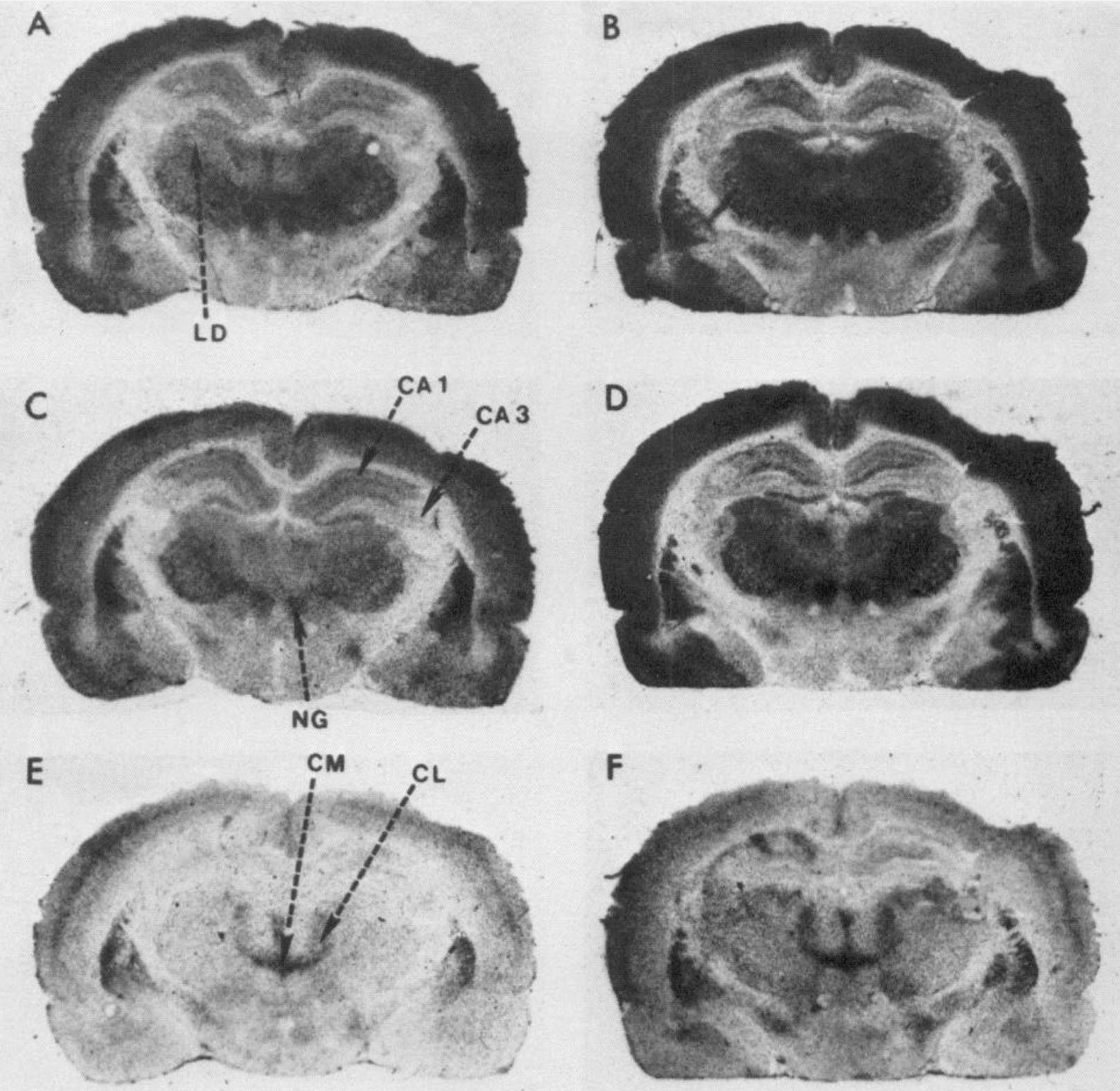

G

H

Figure 4. Autoradiograms of the binding of ${ }^{125}$ I-IPIN to rat brain sections at a level corresponding to Paxinos and Watson (1982) level 23 . Incubation conditions and the generation of autoradiograms are described in Materials and Methods. Comparisons of control $(A, C, E, G)$ and 6-OHDA-treated $(B, D, F, H)$ animals are made for total $\beta$-adrenergic receptors $(A, B), \beta_{1}$-adrenergic receptors $(C, D), \beta_{2}$-adrenergic receptors $(E$, $F$ ), and nonspecific binding sites $(G, H)$. $L D$, laterodorsal thalamic nucleus; $C A 1$, field CA1 of Ammon's horn; $C A 3$, field CA3 of Ammon's horn; $N G$, nucleus gelatinosus; $C M$, central medial thalamic nucleus; $C L$, central lateral thalamic nucleus. 


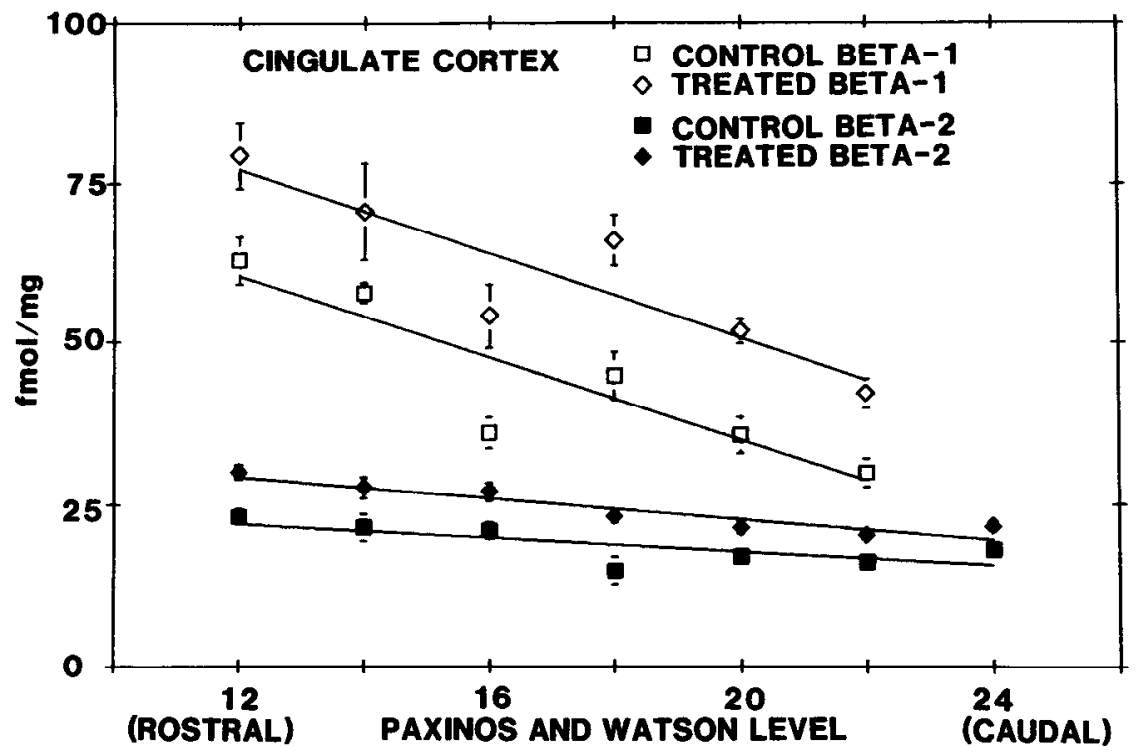

Figure 5. Gradient of subtypes of $\beta$ adrenergic receptors in the cingulate cortex of rat brain. The numbers along the $x$-axis correspond to plate numbers in the Paxinos and Watson atlas (1982). Higher plate numbers indicate a more caudal plane of section. of $40 \%$ in the number of receptors in the motor cortex of treated animals (Fig. 8, inset).

To determine whether depletion of NE was affecting the results, reserpine $(5 \mathrm{mg} / \mathrm{kg})$ was administered intraperitoneally and animals were killed $24 \mathrm{hr}$ later. This treatment resulted in depletion of $95 \%$ of the forebrain NE as measured by HPLC. Autoradiograms of selected anatomical regions for both control and reserpine-treated tissues were compared. Regions were selected based on the presence of significant changes in the density of either $\beta_{1}$ - or $\beta_{2}$-adrencrgic reccptors after trcatment with 6-OHDA. No significant change in the density of either subtype of $\beta$-adrenergic receptor was detected in any region of the brain after administration of reserpine (data not shown).

\section{Discussion}

The initial goal of these experiments was to investigate the effects of 6-OHDA on the density and distribution of subtypes of

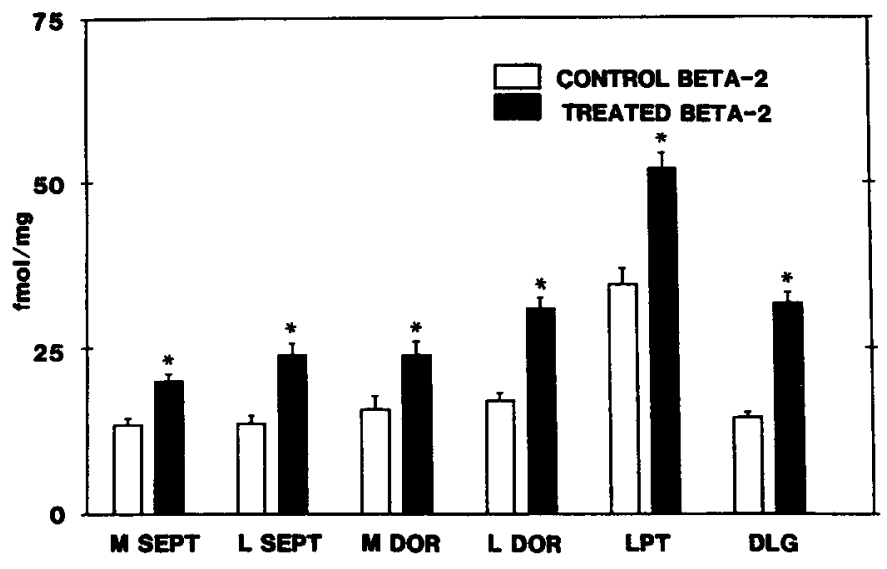

Figure 6. Effect of 6-OHDA on the density of $\beta_{2}$-adrenergic receptors in rat forebrain and thalamic nuclei. The regions analyzed are described in Paxinos and Watson (1982). MSEPT, medial septal nucleus; $L S E P T$, lateral septal nucleus; $M D O R$, mediodorsal thalamic nucleus; $L D O R$, laterodorsal thalamic nucleus; $L P T$, lateral posterior thalamic nucleus; $D L G$, dorsal lateral geniculate nucleus. $\left({ }^{*} p \leq 0.01\right)$ $\beta$-adrenergic receptors by applying the technique of quantitative autoradiography. The high degree of spatial resolution that can be obtained with this technique makes it possible to detect changes in the density of receptors in relatively small areas of the CNS.

A problem common to most studies using autoradiographic techniques involves matching anatomical levels from different brains. By taking every ninth section for cresyl violet staining and using these sections to match the various anatomical regions of the treated and control brains, it was possible to align all of the brains to within $100-200 \mu \mathrm{m}$ in a rostral-to-caudal direction.

A $400 \mu \mathrm{g}$ dose of $6-\mathrm{OHDA}$ was effective in reducing regional NE levels to less than $5 \%$ of control values. Gershanik et al. (1979) suggested that there may be an unequal depletion on the 2 sides of the brain following unilateral injections of 6-OHDA. Administration of either $200 \mu \mathrm{g}$ injections bilaterally on day 1 or $100 \mu \mathrm{g}$ injections bilaterally on days 1 and 2 resulted in high

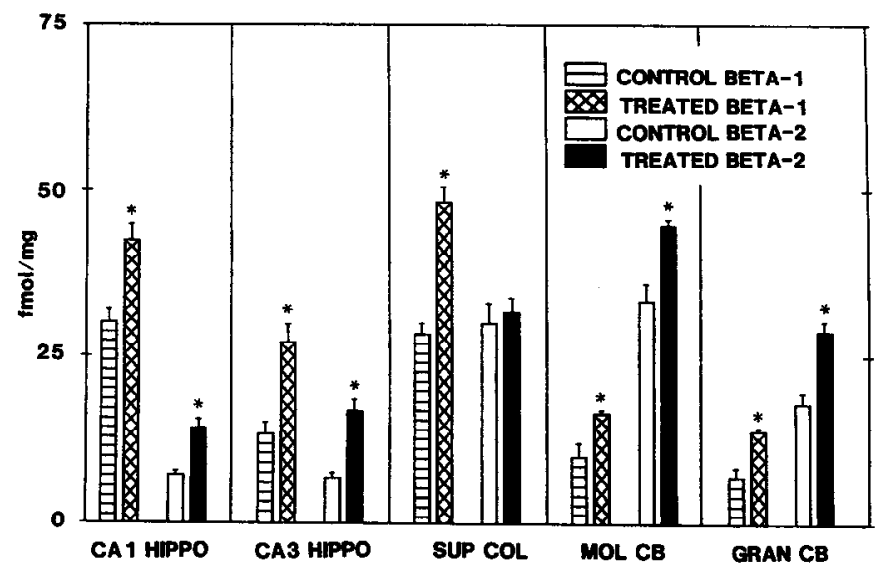

Figure 7. Effect of 6-OHDA on the density of subtypes of $\beta$-adrenergic receptors in caudal and cerebellar regions of rat brain. Regions are described in Paxinos and Watson (1982). CAI HIPPO, field CA1 of Ammon's horn; CA3 HIPPO, field CA3 of Ammon's horn; SUP COL, superior colliculus, superficial gray layer; $M O L C B$, molecular layer of the cerebellum; GRAN $C B$, granular cell layer of the cerebellum. (* $p$ $\leq 0.01)$ 


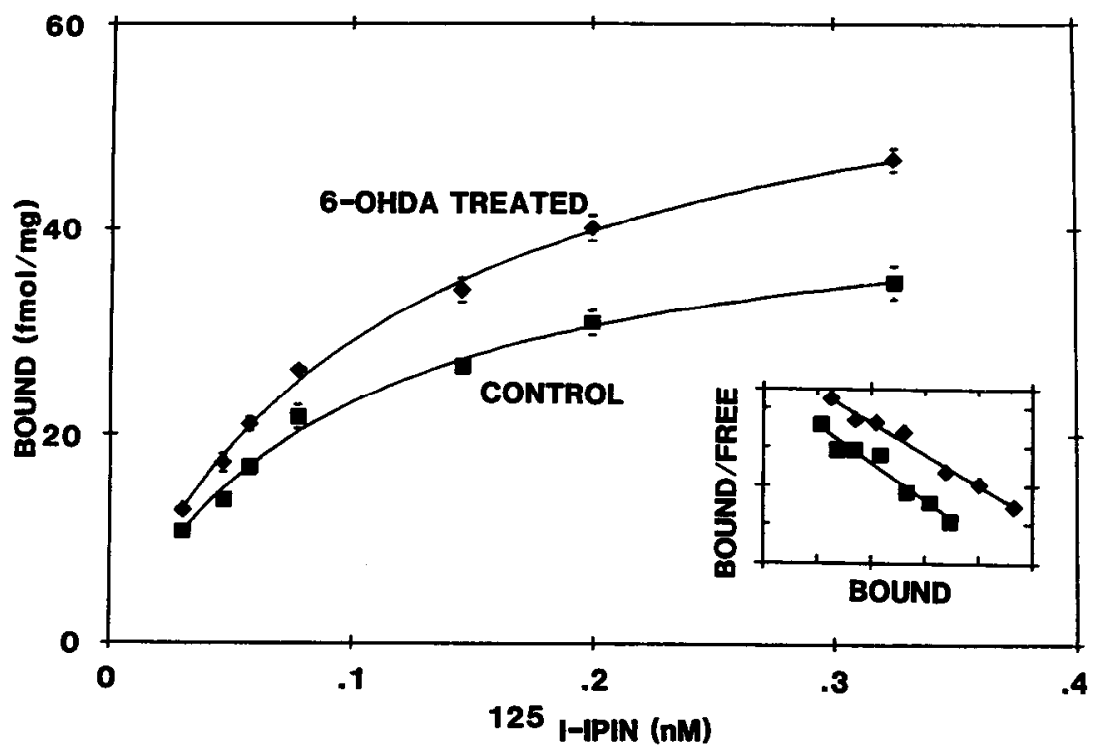

Figure 8. Densitometric analysis of saturation binding in the motor cortex in sections of the rat brain. Sequential coronal $32 \mu \mathrm{m}$ sections of rat brain corresponding to Paxinos and Watson (1982) levels 12-14 were incubated with increasing concentrations of 125 I-IPIN with or without 100 $\mu \mathrm{M} l$-isoproterenol for $60 \mathrm{~min}$ at $24^{\circ} \mathrm{C}$. The sections were then washed for $30 \mathrm{~min}$ in buffer at $4^{\circ} \mathrm{C}$. Autoradiograms were generated and analyzed as described in Materials and Methods. The mean values \pm SEM are plotted $(n=6)$ for specific binding for control $(\square)$ and 6-OHDA-treated $(\bullet)$ animals. Inset, Scatchard transformation of the mean values obtained above. The mean values obtained from Scatchard transformation of the values for $6^{125}$ I-IPIN saturation curves were: $K_{d}, 104 \pm 13$ and $122 \pm 10 \mathrm{pM}$, for control and treated animals, respectively; $B_{\max }, 47 \pm 3$ and 64 $\pm 4^{*} \mathrm{fmol} / \mathrm{mg}$, for control and treated animals, respectively. ${ }^{*}=p \leq 0.01$.

mortality $(>50 \%)$ in the treated animals. This was not the case when the dose was delivered as a $200 \mu \mathrm{g}$ dose unilaterally on day 1 followed by $200 \mu$ g administered on the contralateral side on day 2. Under these conditions there was no indication of any laterality in the degree of depletion since the degree of depletion was greater than $95 \%$ on both sides of the forebrain 2 weeks after treatment. The higher survival rate led us to use the sequential $200 \mu \mathrm{g}$ contralateral injections for our studies. This procedure resulted in depletion of greater than $90 \%$ of the NE from cortex, caudate-putamen, cerebellum, and hippocampus.

Previous investigators using various treatment regimens for the administration of 6-OHDA have reported a $30-60 \%$ increase in the density of $\beta$-adrenergic receptors in the cortex of rats (Sporn et al., 1976, 1977; Harden et al., 1977). In one study, a $60 \%$ increase in the density of $\beta_{1}$-adrenergic receptors was observed in the cortex and no change was seen in the density of $\beta_{2}$-adrenergic receptors (Minneman et al., 1979a). This study was carried out using tissue homogenates from adult rats treated subcutaneously with 6-OHDA while neonates. In the present study, increases in the densities of both $\beta_{1}$ - and $\beta_{2}$-adrenergic receptors were observed in regions of the cerebral cortex after treatment with 6-OHDA. Increases in the density of $\beta_{1}$-adrenergic receptors ranged from 30 to $50 \%$ depending on the cortical region being analyzed. The density of $\beta_{1}$-adrenergic receptors increased in all of the cortical regions examined. The density of $\beta_{2}$-adrenergic receptors did not change in all cortical regions and increased around $30 \%$ in the regions where the density was changed. Although $\beta_{2}$-adrenergic receptors make up only a small percentage of total cortical $\beta$-adrenergic receptors, it is surprising that these increases were not detected in previous studies. The recent availability of highly selective antagonists such as ICI 89,406 and ICI 118,551 , which are up to 1000 -fold selective in contrast to agents such as practolol and zinterolol that were used in the earlier studies and which are only 30-fold selective, may explain the differences in the results observed. Another possible explanation for the discrepancy between previous reports and the present data is the fact that in the earlier reports of studies with subtypes of $\beta$-adrenergic receptors, the animals were treated as neonates with 6-OHDA (Minneman et al., 1979a, b). It has been suggested that neonatal administration of 6-OHDA rcsults in a somewhat more selective depletion of NE, sparing dopaminergic neurons from destruction. While we noted far less depletion of DA than NE after intraventricular administration, it is possible that neonatal administration of 6-OHDA has different effects from those observed after intraventricular administration of 6-OHDA to adult rats.

The changes observed in the cerebellum differ from those previously obtained in our laboratory. Wolfe et al. (1982) examined effects of intracisternal injections of 6-OHDA on the density of subtypes of $\beta$-adrenergic receptors in the cerebellum. An increase in the density of $\beta_{1}$-adrenergic receptors but no change in the density of $\beta_{2}$-adrenergic receptors was observed. Additionally, no significant increase in the total density of $\beta$-adrenergic receptors was observed. Our observations suggest that there is a large change in the density of $\beta_{1}$-adrenergic receptors and a small change in the density of $\beta_{2}$-adrenergic receptors. The different routes of administration of 6-OHDA in the 2 studies may be responsible for the differing observations. Alternatively, as noted above, differences in selectivity of the drugs used to measure the 2 subtypes of receptor may account for the differences in the observed results.

The increases in the binding of ${ }^{125}$ I-IPIN seen in animals treated with 6-OHDA could be explained in several ways. Scatchard analysis was used to test the possibility that treatment with 6-OHDA may have increased the affinity of the subtypes of $\beta$-adrenergic receptors for ${ }^{125}$ I-IPIN rather than the number of $\beta$-adrenergic receptors (Fig. 8). These data revealed an in- 
crease in the density of receptors with no change in the affinity of the receptor for ${ }^{125}$ I-IPIN after treatment with 6-OHDA. Another possibility is that the increase in the density of $\beta$-adrenergic receptors in animals treated with 6-OHDA could also be due to the "unmasking" of $\beta$-adrenergic receptors brought about by the depletion of endogenous catecholamines. Treatment with 6-OHDA resulted in the depletion of greater than $90 \%$ of the NE in a number of brain regions. The role of this hypothetical unmasking in the apparent increase in the density of the subtypes of $\beta$-adrenergic receptors was investigated by administering reserpine to bring about an equivalent reduction in NE content. Because the effects of reserpine on NE levels occur rapidly and tissue for the assay of the subtypes of $\beta$-adrenergic receptors was prepared within $24 \mathrm{hr}$ of reserpine treatment, it is unlikely that proliferation of $\beta$-adrenergic receptors would occur to complicate the interpretation of the results. The densities of receptors in the regions analyzed were similar to those in the same regions in control animals. These results suggest that depletion of endogenous NE was not responsible for the apparent increase in the densities of the subtypes of $\beta$-adrenergic receptors seen after treatment with 6-OHDA.

These observations, in conjunction with the anatomical distribution of the observed changes, support the following conclusions: (1) Subtypes of $\beta$-adrenergic receptors are distributed heterogeneously within the rat brain; (2) the relative percentages of each subtype of $\beta$-adrenergic receptor within a region vary widely, as does the overall distribution of total $\beta$-adrenergic receptors throughout the rat brain; and (3) the changes observed after treatment with 6 -OHDA suggest that, within a given region, the subtypes of $\beta$-adrenergic receptors may be independently regulated. No correlation between changes in the densities of $\beta_{1}$-or $\beta_{2}$-adrenergic receptors was observed within a particular structure. There were regions where the density of $\beta_{1}$-adrenergic receptors increased and that of $\beta_{2}$-adrenergic receptors did not and regions where the density of $\beta_{2}$-adrenergic receptors increased and that of $\beta_{1}$-adrenergic receptors did not. There were also regions where the densities of both subtypes increased and regions where the densities of neither subtype changed.

The widespread and marked increases in the densities of $\beta_{2}$ adrenergic receptors after the destruction of adrenergic innervation by 6-OHDA supports the hypothesis that, at least in some regions, $\beta_{2}$-adrenergic receptors may be functionally innervated.

\section{References}

Anton, A. H., and D. F. Sayre (1962) A study of the factors affecting the alumina oxide-trihydroxyindole procedure for the analysis of catecholamines. J. Pharmacol. Exp. Ther. 138: 360-375.

Bradford, M. M. (1976) A rapid and sensitive method for the quantitation of microgram quantities of protein utilizing the principle of protein-dye binding. Anal. Biochem 72: 248-254.
Gershanik, O. S., R. E. Heikkila, and R. C. Duvoisin (1979) Asymmetric action of intraventricular monoamine neurotoxins. Brain Res. 174: 345-350.

Hancock, A. A., A. L. DeLean, and R. J. Lefkowitz (1979) Quantitative resolution of beta-adrenergic receptor subtypes by selective ligand binding: Application of a computerized model fitting technique. Mol. Pharmacol. 16: 1-9.

Harden, T. K., B. B. Wolfe, J. R. Sporn, B. K. Poulos, and P. B. Molinoff (1977) Effect of 6-hydroxydopamine on the development of the beta adrenergic receptor/adenylate cyclase system in rat cerebral cortex. J. Pharmacol. Exp. Ther. 203: 132-143.

Iversen, L. L., and N. J. Uretsky (1970) Regional effects of 6-hydroxydopamine on catecholamine containing neurones in rat brain and spinal cord. Brain Res. 24: 364-367.

Kalisker, A., C. O. Rutledge, and J. P. Perkins (1973) Effect of nerve degeneration by 6-hydroxydopamine on catecholamine-stimulated adenosine 3',5'-monophosphate formation in rat cerebral cortex. Mol. Pharmacol. 9: 619-629.

Kostrzewa, R. M., and D. M. Jacobowitz (1974) Pharmacological action of 6-hydroxydopamine. Pharmacol. Rev. 26: 199-288.

Minneman, K. P., and P. B. Molinoff (1980) Classification and quantification of $\beta$-adrenergic receptor subtypcs. Biochcm. Pharmacol. 29: 1317-1323.

Minneman, K. P., M. D. Dibner, B. B. Wolfe, and P. B. Molinoff (1979a) $\beta_{1}$ - and $\beta_{2}$-adrenergic receptors in rat cerebral cortex are independently regulated. Science 204: 866-868.

Minneman, K. P., L. R. Hegstrand, and P. B. Molinoff (1979b) Simultaneous determination of $\beta_{1}$ - and $\beta_{2}$-adrenergic receptors in tissue containing both receptor subtypes. Mol. Pharmacol. 16: 34-46.

Neve, K. A., P. McGonigle, and P. B. Molinoff (1986) Quantitative analysis of the selectivity of radioligands for subtypes of beta adrenergic receptors. J. Pharmacol. Exp. Ther. 238: 46-53.

Palmer, G.C. (1972) Increased cyclic AMP response to norepincphrinc in the rat brain following 6-hydroxydopamine. Neuropharmacology 11: $145-149$.

Paxinos, G., and C. Watson (1982) The Rat Brain in Stereotaxic Coordinates, Academic, New York.

Rainbow, T. C., L. V. Bleisch, A. Biegon, and B. S. McEwen (1982) Quantitative densitometry of neurotransmitter receptors. J. Neurosci. Methods 5: 127-138.

Rainbow, T. C., B. Parsons, and B. B. Wolfe (1984) Quantitative autoradiography of $\beta_{1}$ - and $\beta_{2}$-adrenergic receptors in rat brain. Proc. Natl. Acad. Sci. USA 81: 1585-1589.

Sachs, C. H., and G. Jonsson (1975) Fffect of 6-hydroxydopamine on central noradrenaline neurons during ontogeny. Brain Res. 99: 277291

Scatchard, G. R. (1949) The attractions of proteins for small molecules and ions. Ann. NY Acad. Sci. 51: 660-672.

Sporn, J. R., T. K. Harden, B. B. Wolfe, and P. B. Molinoff (1976) $\beta$-Adrenergic receptor involvement in 6-hydroxydopamine-induced supersensitivity in rat cerebral cortex. Science 194: 624-626.

Sporn, J. R., B. B. Wolfe, T. K. Harden, and P. B. Molinoff (1977) Supersensitivity in rat cerebral cortex: Pre- and postsynaptic effects of 6-hydroxydopamine at noradrenergic synapses. Mol. Pharmacol. 13: $1170-1180$.

Uretsky, N. J., and L. L. Iversen (1970) Effects of 6-hydroxydopamine on catecholamine containing neurones in the rat brain. J. Neurochem. 17: 269-278.

Wolfe, B. B., K. P. Minneman, and P. B. Molinoff (1982) Selective increases in the density of cerebellar $\beta_{1}$-adrenergic receptors. Brain Res. 234: 474-479. 